\title{
Review
}

\section{Large Genetic Animal Models of Huntington's Disease}

\author{
A. Jennifer Morton ${ }^{\mathrm{a}, *}$ and David S. Howland ${ }^{\mathrm{b}, *}$ \\ ${ }^{\mathrm{a}}$ Department of Physiology, Development and Neuroscience, University of Cambridge, Cambridge, UK \\ ${ }^{\mathrm{b}}$ CHDI Foundation/CHDI Management, NJ, USA
}

\begin{abstract}
The dominant nature of the Huntington's disease gene mutation has allowed genetic models to be developed in multiple species, with the mutation causing an abnormal neurological phenotype in all animals in which it is expressed. Many different rodent models have been generated. The most widely used of these, the transgenic R6/2 mouse, carries the mutation in a fragment of the human huntingtin gene and has a rapidly progressive and fatal neurological phenotype with many relevant pathological changes. Nevertheless, their rapid decline has been frequently questioned in the context of a disease that takes years to manifest in humans, and strenuous efforts have been made to make rodent models that are genetically more 'relevant' to the human condition, including full length huntingtin gene transgenic and knock-in mice. While there is no doubt that we have learned, and continue to learn much from rodent models, their usefulness is limited by two species constraints. First, the brains of rodents differ significantly from humans in both their small size and their neuroanatomical organization. Second, rodents have much shorter lifespans than humans. Here, we review new approaches taken to these challenges in the development of models of Huntington's disease in large brained, long-lived animals. We discuss the need for such models, and how they might be used to fill specific niches in preclinical Huntington's disease research, particularly in testing gene-based therapeutics. We discuss the advantages and disadvantages of animals in which the prodromal period of disease extends over a long time span. We suggest that there is considerable 'value added' for large animal models in preclinical Huntington's disease research.
\end{abstract}

Keywords: CAG repeat, polyglutamine, sheep, non-human primate, monkey, minipig, neurodegeneration, sleep, circadian

\section{INTRODUCTION}

Neurological diseases such as Huntington's disease (HD), Alzheimer's disease (AD), Parkinson's disease (PD), schizophrenia and depression are complex in their manifestation, with symptoms that encompass motor, cognitive and psychiatric domains. Animal models of such diseases are invaluable tools that can be used for both understanding the mechanisms underlying pathology of neurological disorders, and also

*Correspondence to: David Howland, CHDI Management/CHDI Foundation, 300 Alexander Park, Suite 110, Princeton, NJ, 08543, USA. Tel.: +1 609945 9046; Fax: +1 609243 0180; E-mail: david.howland@chdifoundation.org. or Jenny Morton, Dept. of Physiology, Development and Neuroscience, University of Cambridge, Downing Street, Cambridge CB2 3DY. E-mail: ajm41@cam.ac.uk. testing potential therapies. But the insights gained from different animal models vary markedly, depending on the model. Many neurodegenerative disorders, including HD, are uniquely human conditions. Therefore, we should not expect that any genetically modified animal used to model HD can recapitulate fully the pathophysiology and progression of the human disease.

HD is caused by a single dominant gene mutation that is an expanded CAG repeat in the HTT gene [1]. Although it is a rare disease, the fact that it is a single gene disorder makes it a 'paradigm' disease. That is, if we can develop a strategy for successfully treating $\mathrm{HD}$, then there is an increased likelihood that we will be able to develop treatments for more genetically complex diseases such as AD. In 1993 when the HD gene was cloned, the expectation was, both within and outside the HD field that with the discovery of the 
gene would come immediate insight into the mechanisms underlying HD. But, not only was the nature of the mutation causing HD novel, the gene encoded for a protein that was hitherto unknown [1]. Furthermore, the expression of the huntingtin gene (HTT) gene and protein (HTT) was not specific to the striatum, the site of primary pathology in HD. In fact, it is not neuronspecific, or even brain-specific [2, 3]. A further twist comes from recent evidence suggesting that, although there is considerable evidence for toxicity arising from a gain of function of mutant HTT (for discussion, see $[4,5])$, the gene product may not be the only toxic entity in HD. It seems increasingly likely that a contribution to the toxicity might arise from toxic mRNA or via aberrant transcription of the gene $([6,7]$; for reviews, see $[8,9])$. Nevertheless, our understanding of the pathophysiology and clinical features of HD has grown steadily since $1993([10,11]$ for a selection of reviews, see [12-22]). Importantly, although as yet there is no disease-modifying therapy these available $[23,24]$, there are several promising novel therapeutic strategies that are currently being developed [25-27]. Thus, while any expectations of a therapeutic 'quick fix' have been dashed, our understanding of HD is more comprehensive than ever before, and significant effort is being directed towards therapeutic development.

Given that HD is caused by a single gene mutation, in recent years much effort has been directed towards gene silencing approaches that target the mutant HTT mRNA and protein. In addition, efforts are being directed to deliver gene therapies expressing trophic factors to attempt to slow neurodegeneration in HD. Such approaches hold great promise, provided the therapeutic agents such as trophic factors (e.g. BDNF) or antisense oligonucleotides and siRNAs [25, 28, 29] can be delivered effectively to the areas of the brain in which they are needed. However, since these novel therapies have rarely been used in humans, and never in HD patients, several issues need to be addressed before they can move to the clinic. These include whether or not (i) adequate and appropriate biodistribution of the agent can be achieved in the human brain; (ii) the pharmacokinetic parameters are satisfactory (in particular, whether or not a sufficient dose can be delivered to the target site and be efficacious); and (iii) they can be used safely. This last point is particularly relevant, since gene therapies might be active for long periods, and may not be reversible. In addition, many of these novel gene-based therapies are likely to require the use of invasive delivery methods to the brains of patients and such delivery methods are mostly unproven [26]. Finally, potential side-effects of direct delivery, such as inflammatory reactions (e.g. encephalitis), neoplasms (tumours), and unknown changes in neuronal function or metabolism, need to be determined for both short- and long-term exposure. For some therapies, the most efficient method of delivery is undetermined, and improving distribution in brain tissues will need further exploration.

\section{SMALL ANIMAL (RODENT) MODELS OF HD}

Numerous transgenic mouse and rat and knockin mouse models of HD are available for preclinical research (refs [30-42] in Table 1). Genetic engineering technology is well advanced in rodents, and this has allowed the creation of transgenic (carrying gene fragments or the full-length gene), as well as knockin mouse models of HD carrying varying sizes of the CAG repeat expansion (e.g. allelic series) inserted into the mouse $H t t$ gene. Mice in particular are cheap and sustainable laboratory animals, and our understanding of HD has greatly benefited from the accessibility of mouse models. Investigators studying HD are fortunate in that they are able to choose to use the model that is best suited to address their biological questions. The use of mouse models has been very fruitful, and genetically engineered rodent models have provided good insight into the pathology of $\mathrm{HD}$, including an estimate of the extent of the repertoire of changes in gene expression [43], the discovery of neuronal intranuclear inclusions [44], and other aspects of HD such as cognitive dysfunction, and the sleep and circadian disorders that were previously not well recognized as being part of the repertoir of HD symptoms $[17,45]$. There are several excellent reviews of the rodent models of HD (see Table 1 and ref [46]) and we do not intend to review these models in detail in this article.

\section{LIMITATIONS OF SMALL ANIMAL MODELS OF HUNTINGTON'S DISEASE}

There should be little debate about the importance of rodent models of HD in preclinical research and development. Nevertheless, there are three issues associated with the use of small animals that cannot be addressed by further technological developments.

The first is that mice are short-lived. This necessarily restricts the study of neurological disease in mouse models to a short time period. However, most human neurodegenerative diseases take many years to appear, 


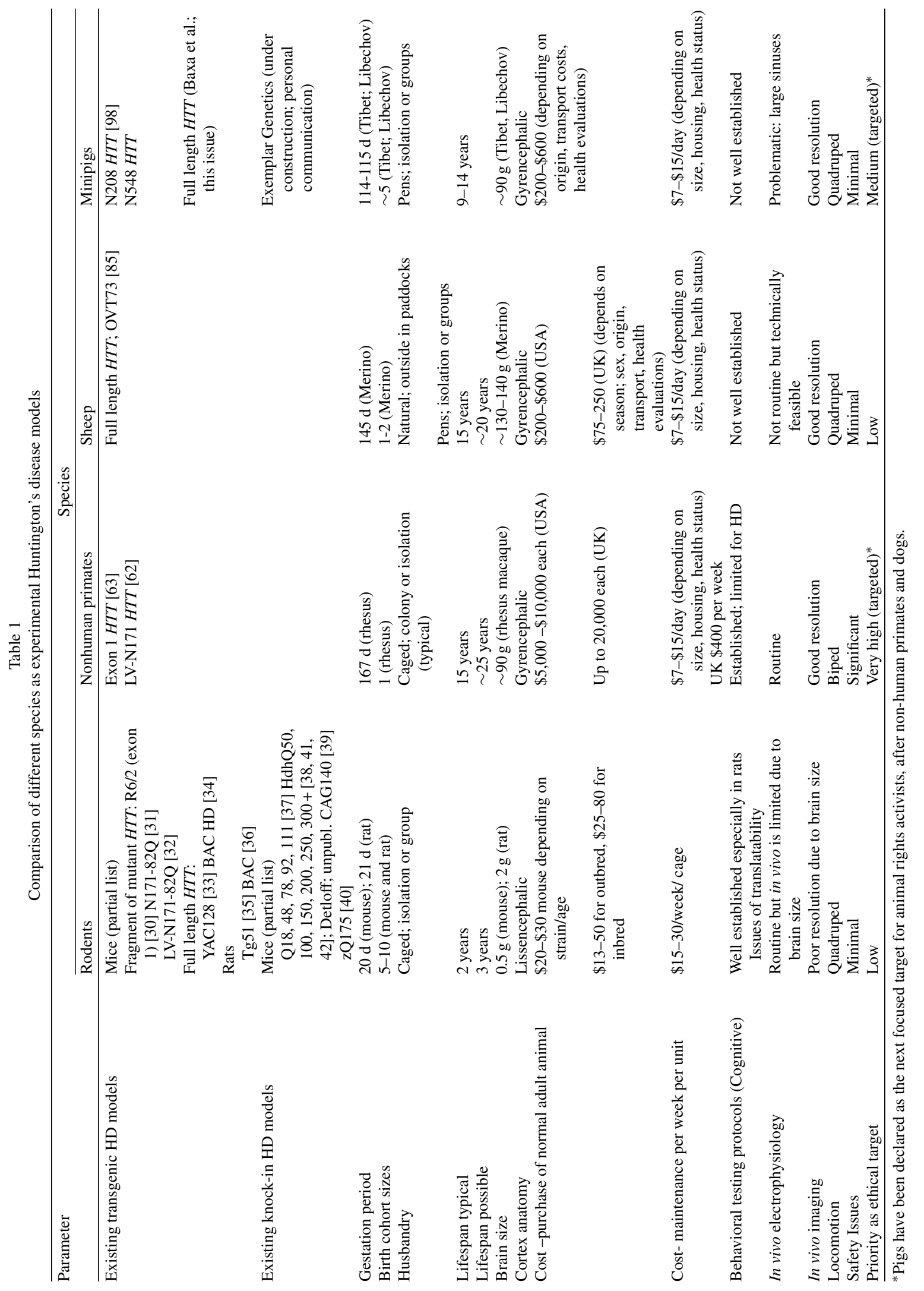


with HD typically taking 40 or so years to manifest. Time from post-manifest to the end of illness may be up to 25 years. Thus, even if mice become symptomatic, their short lifespan excludes the possibility of extended study. It is not clear if 'clock' time or percentage of normal life span is the critical variable. Irrespective, large animal models would provide the potential for studying HD over a clock time that is closer to the time over which the human condition develops (i.e. 5-10 years or longer).

The second is that rodents in general, and mice in particular, have small brains (Fig. 1). This has an impact on both research application and therapeutic development. For example, advanced measurement techniques such as in vivo imaging and in vivo electrophysiology cannot be applied optimally in mice. Some of the most important recent advances in neurology have been the development of techniques for examining brain function in vivo (magnetic resonance imaging (MRI) and positron emission tomography (PET) scanning), but the resolution of many scanners is an area barely smaller than the mouse striatum. Similarly, with recording techniques such as electroencephalography (EEG), their small brain size means that only 1-2 recording electrodes are typically used on a mouse, compared to 16-22 on a typical human EEG recording (Table 1). Most important for therapeutic development is that delivery of any treatment that is effective in a mouse will need to be 'scaled-up' for humans, particularly for those that need to be delivered directly into the brain, such as trophic factor infusion, transplant therapies, and gene therapies. But it is not clear if this scaling up will need to be done arithmetically, or if larger brains will need relatively less (or more) drug delivered.

The third issue is that rodent brains lack some of the major neuroanatomical characteristics of the human brain. Of particular relevance to HD, in which pathology probably starts in basal ganglia and/or cortex, is that there are major differences in the anatomy of basal ganglia in human and mouse. For example, mice do not have separate caudate and putamen, nor do they have neuromelanin in the substantia nigra and the functional organisation of their basal ganglia is different from that of primates. Furthermore, mice have lisencephalic (smooth) cortices (Fig. 1). The large volume of the human cortex is made even more so by its gyrencephalic (convoluted) anatomy. The human cerebral cortex has a surface area of $2500 \mathrm{~cm}^{2}$ that far exceeds that of a rat that has a surface area of is $6 \mathrm{~cm}^{2}$. (For more details of neuroanatomical comparisons, see ref [110]). This evolutionary advantage of humans is going

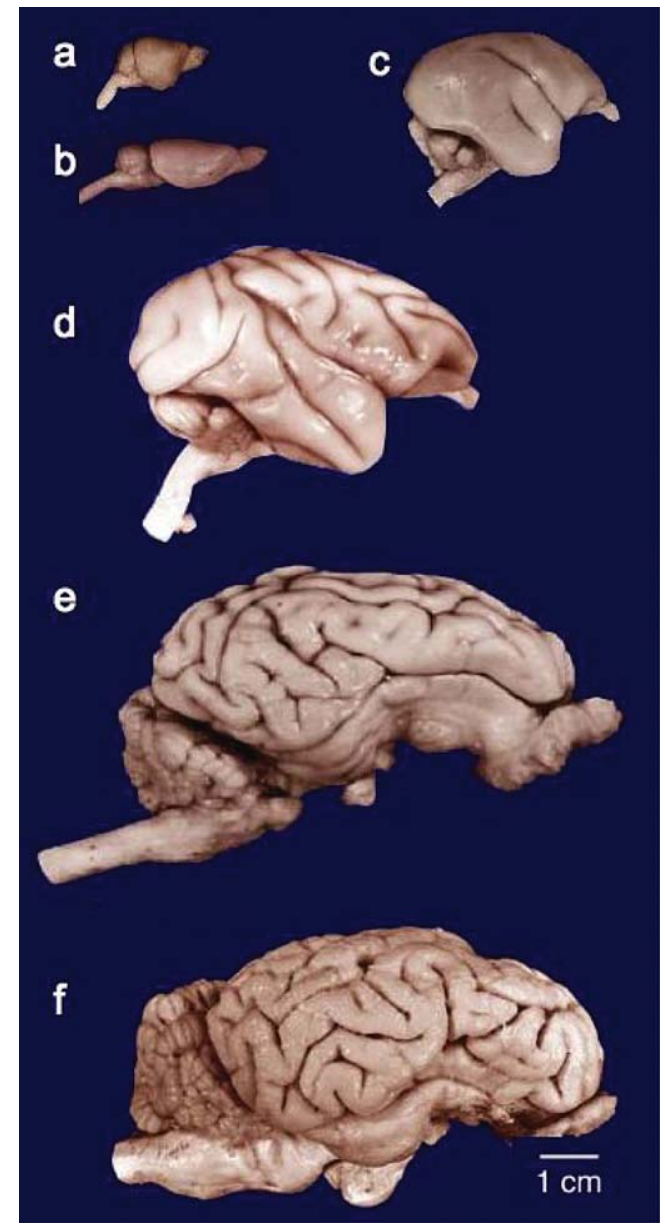

Fig. 1. Comparative brain sizes of species that could be used for modeling neurodegenerative brain disorders. Species illustrated with lissencephalic cortices include house mouse (Mus musculus; a), brown rat (Rattus norvegicus; b) and common marmoset (Callithrix jacchus; c). Those with gyrencephalic cortices include Rhesus monkey (Macaca mulatta; d), pig Sus scrofula domesticus; e) and sheep (Ovis aries domestica; f). The images came from the University of Wisconsin and Michigan State Comparative Mammalian Brain Collections

to pose a particular challenge if therapies need to be delivered to the cortex. The lack of the gyrencephalic cortex may be a particularly important limitation of the use of rodent models, if therapies need to be targeted to this region.

\section{THE 'VALUE ADDED' BY THE AVAILABILITY OF LARGE ANIMAL MODELS OF HUNTINGTON'S DISEASE}

It has been argued that information gained from using small animals as models is 'good enough' to 
allow us to go straight to the clinic. Conversely, it has been argued that animal models per se are irrelevant to the human condition. There is also the argument that there are plenty of humans who could be recruited for preclinical studies. But there are several reasons why we think animal models are still needed. For example, the link between gene mutation, brain pathology and symptoms in HD is unknown. While MRI, functional MRI and computer tomography (CT) scans give useful readouts of disease-related changes in structure and function [47-50], they do not inform us about cellular pathology. Brain biopsy in humans is not feasible for practical or ethical reasons, and even if it were, with a disease such as HD that differentially affects areas of the brain, results of a biopsy from one area would not necessarily be representative of what is happening in another. Post mortem analysis of tissue is important, but represents a single snapshot in time and is typically at end-stage disease. Studies of end-stage tissue necessarily represent a compendium of events that comprise the toxicity of the mutant gene and its product, as well as a myriad of compensatory sequelae. Understanding the relationship between brain physiology and symptoms in HD would be a key advance that would clarify our understanding of the relationship between HD pathogenesis and its symptomatic progression. It would allow us to identify physiological consequences of the earliest brain changes manifest in neurological disease. It is particularly difficult at present to study the mechanisms underlying conversion from pre-manifest to manifest stages, or even to define those stages unambiguously. Large animals that model pre-manifest (prodromal) HD over a protracted time course would therefore represent a valuable resource with which to study this process systematically. Of course, with the advantages of a relevant timescale come caveats that need be considered carefully. Critically, the cycle time for studies using large animals will be greatly extended compared to such work done in rodents. In addition, feasibility for the average investigator to use large HD animal models will be limited, further restricting the extent of investigation. (See further discussion below).

As well as the difficulties that come with direct studies of human brain, human research participants are a valuable resource that should not be squandered. Although large cohorts of HD patients and premanifest gene carriers are potentially available for clinical trials [51, 52], there are serious ethical and legal constraints on doing experiments with humans, however well informed they might be. And there will be new ethical issues to tackle once multiple potential ther- apies come on line. For example, once patients are entered for a clinical trial, they cannot be entered for a second trial unless they withdraw from the first. Of particular importance, especially for novel gene therapy or direct protein therapeutic strategies currently being developed, is the need to investigate adequate and appropriate biodistribution, efficacy and safety of these agents prior to advancing into humans. Preclinical studies in rodent models are a clear starting point for gene therapy investigations for HD. However, since all the data should be more directly translatable to the large human brain, moving to larger brained animal models after promising results are obtained in rodents, is a logical (and possibly necessary) step for optimizing delivery and biodistribution, validating on-target mechanism of action, and assessing safety profiles (Fig. 2). Some studies can be done in normal large animals but given that key outcome measures required for preclinical development are likely to be affected by the expression of mutant HTT in the brain, it will be important to at least attempt to advance these studies in large animal HD models.

\section{NON-HUMAN PRIMATE MODELS OF HUNTINGTON'S DISEASE}

The ideal animal model for studying human neurodegenerative diseases would be a large non-human primate. Great apes such as chimpanzee, orangutan and bonobo are humanoid and have an estimated $98 \%$ of their genome identical to humans and large complex brains that are anatomically very similar to ours. However, the great apes cannot be used for research in the European Union, and there is pressure for a similar ban to be introduced in the USA (see for example, ref [53]). In 2008, The Great Ape Protection Act was introduced to Congress, proposing an end to invasive research and testing of great apes confined within US laboratories. This is already underway, with new research being suspended, and ongoing research being phased out.

The next best theoretical species would be nonhuman primates such as monkeys, since although their brains are much smaller than those of apes; their genomes and brains (Fig. 1) are similar to humans. A number of different species of monkey have been used for safety studies for neurodegenerative indications (for examples, see references [54-56]) as well as for preclinical studies aimed at cognition (for examples, see references [57-59]). Some neurochemical lesion monkey models of HD have been developed [60, 61], 
although they are not commonly used. This is because while they are useful for modeling certain aspects of the motoric impairments and striatal cell loss that is seen in HD, the fact that (i) they are not progressive, (ii) damage is limited to the area(s) directly related to the lesion, and (iii) they do not express the mutant gene, makes them insufficient for modeling a broad range of symptoms and HD pathophysiology.

\section{LENTIVIRUS NON-HUMAN PRIMATE HUNTINGTON'S DISEASE MODELS}

Palfi et al. [62] were the first to report on a genetic non-human primate model for HD. This group used a lentivirus encoding a fragment of human mutant $H T T$ (HTT171-82Q) that was injected directly into the dorsolateral sensorimotor striatum of rhesus macaques. The virus was injected unilaterally, and treated animals that were tested with apomorphine (a dopamine agonist) showed signs of chorea, dystonia and ipsilateral turning. Histological examination of the infected striatum showed evidence of neuritic and nuclear HTT aggregates, reactive gliosis and neuronal cell loss. Bilateral injections of the HTT171-82Q virus into dorsolateral striatum resulted in dyskinesia that appeared slowly and then persisted for 30 weeks.

The lentivirus approach has clear disadvantages as well as advantages. The main limitation is that, as with excitotoxic lesions, the restricted expression of mutant HTT in the brain limits the recapitulation of the spectrum of HD pathophysiology. An advantage of the lentivirus model is that since lentiviral injection does not require the generation of germline transgenic animals, the timelines for study are accelerated. Furthermore, since different variations of the HTT gene and mutation can be generated, lentivirustreated animals could be used to investigate the impact on resulting pathology and behavior of different sized fragments of mutant HTT and/or CAG repeat length. Although these models may have only limited utility because of local/restricted mutant HTT expression, the effects of mutant HTT on local neuronal environments can be analyzed. An example of this would be using lentivirus-infected striatum to study pharmacodynamic effects of the local infusion of a gene therapy aimed at reducing mutant HTT expression. Injections of the lentiviruses could also be used to study the impact of mutant HTT expression in different brain regions and circuits. Finally, the described work has already opened the door to investigators pursuing germline transgenic models of HD.

\section{GERMLINE TRANSGENIC NON-HUMAN PRIMATE HUNTINGTON'S DISEASE MODELS}

Yang et al. [63, 64] used lentiviral-mediated transgenesis to microinject a human exon 1 HTT gene fragment with $84 \mathrm{Q}$ and a lentivirus expressing GFP into the perivitelline space of rhesus macaque oocytes to generate transgenic animals. Expression of the mutant HTT was driven by the strong constitutive human polyubiquitin $\mathrm{C}$ promoter. Five live newborn founder animals were delivered at term. In these five animals, there was a range in CAG repeat size in the integrated transgenes (from 27 to) indicating that either variants of transgene DNA were present in the DNA preparations used for microinjection, or there was instability of the CAG repeat size during virus production or transgene integration in the embryos. Two of the transgenic animals died perinatally. These animals had multiple transgene copies inserted with CAG repeat sizes of 88 and 27/65. A third animal died after 1 month and showed signs of dystonia and chorea. This animal also had multiple copies of the transgene inserted (with a CAG repeat size of 84 in each of its copies). A fourth transgenic founder carrying a single copy of the transgene with $83 \mathrm{CAG}$ repeats was reported as normal but died aged 11 months after the article was published (personal communication, A Chan). Histological analyses of brain sections from two of the transgenic animals that died very early showed evidence of widespread mutant HTT inclusions present throughout the brain in nuclei and in neuropil. These inclusions were morphologically identical to those seen in $\mathrm{R} 6 / 2$ mice $[44,65]$.

Further work by this group was done using a microinjected transgene with the ubiquitin promoter driving an exon 1 human mutant HTT gene with 147Q [66]. These transgenic monkeys however did not survive to term, indicating that the higher $\mathrm{Q}$ length in these monkeys was very toxic. A single transgenic founder from the original studies survives at the Yerkes Primate Center today [67]. This animal expresses only a single copy of the transgene carrying 29 CAG repeats. Stems cells [68] and induced pluripotent stem (iPS) cells [69] have been successfully derived from the HD transgenic monkeys providing new valuable cell based models. The Emory group continues its efforts to characterize the living CAG29 transgenic monkey, and have also extended their work to generate additional HD non-human primate transgenic models that have not yet been reported in the literature. 


\section{LIMITATIONS OF THE USE OF HUNTINGTON'S DISEASE MONKEY MODELS}

HD transgenic monkeys may be particularly useful for following early disease development and pathology, and in the application of sensitive imaging techniques (such as MRI and PET) to provide non-invasive measures of disease. Additionally, HD non-human primates could be a valuable resource for studying the effects of mutant HTT on cognition, if such data are translatable to the human condition. Testing of therapeutic candidates using each of these measures would provide valuable preclinical data in terms of both efficacy and safety, helping to inform human clinical trials. However, there are a number of major hurdles to be overcome before non-human primates will be acceptable as a large animal model for use in HD preclinical research (see Table 1). First, although the number of animals that need to be used at any one time would be very small, availability of HD animals will be at a premium. Typically, for behavioural testing in normal animals group sizes of 6-12 are used; for pharmacological safety trials, groups of 12-20 animals are used. Normal monkeys can be obtained relatively easily for experiments, but HD non-human primates would need not only to be developed, but also to be bred in sufficient numbers and maintained until old enough to use in preclinical trials. Also, even normal monkeys are costly to purchase and house. Currently in the USA, typical purchase costs for a rhesus macaque are $\$ 5000-\$ 10,000$, and costs, including for animal maintenance, are higher in the UK (Table 1). Importantly, there are also indirect costs - not least the ethical issues that surround the use of non-human primates for research. Indeed, many universities are reducing their use of non-human primates in response to public antagonism.

In addition to the high costs, the practicalities of housing monkeys with a slowly progressing neurodegenerative disease will be challenging. If the animals manifest HD symptoms that recapitulate the human disorder accurately, we would expect not only motor symptoms, but also psychiatric disorder and cognitive decline. The management of these symptoms in the context of experimental testing presents both a practical and an ethical challenge that will need to be addressed. It is extremely difficult to manage ill animals within a monkey colony. The normal practice is to isolate them so that their medical needs can be managed effectively and safely. For short-term illnesses, this is practicable. But long-term isolation of non-human primates causes stress that would add confounds that are difficult to control. Once animals start to show symptoms, decisions about their optimal care may have serious impact on the nature and duration of experiments. Questions that need addressing include (i) how will isolation stress or experimentation affect the disease progression? (ii) How could this be controlled? (iii) Would there be a need either to treat symptoms (such as depression, psychosis) or to tranquillize monkeys for transport, and if so, how would these affect testing? (iv) At what age should experiments be started? and (v) How large do group sizes need to be for well-powered studies? Finally, human HD patients typically need round the clock nursing care in the last 5-10 years of their lives. This would not be possible with HD monkeys, so it is likely that only pre-manifest and early-mid stage disease could be studied. Diseases such as HD that include psychiatric disturbances could also increase the risk of injury to either the investigators or the animals. Lastly, although transgenic technologies have been established in non-human primates, the technology for making knock-in or gene-targeting modifications in non-human primates has not advanced to the stage where viable animals have been born [70]. The development of HD monkeys is likely to be undertaken by only a small number of investigators, and access to such animals will be limited, and probably beyond the reach of the average investigator.

\section{FARM ANIMAL MODELS OF HUNTINGTON'S DISEASE}

The most commonly used second species for therapeutic testing in Europe is the dog. But to our knowledge, there is no HD research group currently using dogs as experimental animals.

Large brained domesticated farm animals represent interesting possibilities for the development of new models of HD. The farming industry already has developed well-defined systems for breeding, rearing and transporting such animals. However, there are relatively few domesticated animals that might be useful for HD research. Horses, donkeys and cattle are theoretically possible, but they are very large animals, and uniparous with relatively long gestation periods. Thus, the costs of breeding and rearing, as well as the risks and issues of manageability associated with their size, would outweigh any possible advantages. For the remainder of this review therefore we will focus on the potential of sheep and pigs as large models of HD. (Sheep and goats share similar physiological and 
behavioral characteristics, so for simplicity, here we will discuss only sheep).

\section{SHEEP AS MODELS OF HUNTINGTON'S DISEASE}

Sheep fulfill a number of simple practical requirements for a species in which to model HD. They are domesticated, but are relatively outbred. They are docile and pose little risk to the investigator. They normally live in flocks outdoors, so they do not require specialized housing. They are therefore relatively easy to care for and are cheap to maintain. Because sheep can be kept in their natural environment outdoors, there are no issues of impoverishment of environment associated with use of conventional laboratory animals. Furthermore, they are economical to use as research subjects. Sheep do not continue growing throughout their lives. Once they reach maturity, no modifications to their housing and equipment are required. Depending on the breed, their body weight is comparable to an adult human. For example, in a large breed such as the South Australian merino, ewes reach a mature weight of $50-70 \mathrm{~kg}$ by 2 years of age. This makes it feasible to use them for systematic therapeutic testing.

Sheep are long-lived compared to rodents. A mouse is 'old' by 2-2.5 years of age. The natural lifespan of a sheep is typically $12-15$ years, although they are capable of living for $>21$ years. This longer lifespan makes them suitable for studying much later stages of progressive neurological diseases than is possible in rodents.

Physiologically, sheep make practical models. Although they are ruminants, their other body systems are very similar to humans, and they have been widely used as large animal models of reproductive biology, respiratory and cardiovascular physiology, joint surgery and as host organisms for viruses. Their brain biology is less well studied, with the exception of hypothalamic physiology, which in sheep is particularly well understood since their reproductive system is so similar to humans (see for example, ref [71]). Nevertheless, although many aspects of sheep brain physiology have not been extensively studied, some seminal discoveries have been made using sheep, particularly in the field of facial recognition [72, 73]. Furthermore, new directions in the use of sheep, for example as models of cognitive function [74] are emerging.

Their physical size, although a cost disadvantage, is an advantage where experimental designs are concerned. Sheep are strong and can carry a backpack with transmitting devices. This means they can be used for ambulatory telemetry experiments using equipment designed for humans. This cannot be done easily in mice because they are too small, and is difficult to do non-invasively in monkeys, because they are dexterous enough to remove the data collection modules.

\section{SHEEP BRAIN SIZE AND ANATOMY}

One of the best reasons for considering sheep as a large animal model of human brain function is their large brain. An adult human brain weighs 1300-1400 g. Non-human primate brains are also large (an adult orangutan brain weighs $360 \mathrm{~g}$, a rhesus macaque brain weighs 90-97 g). A mouse brain weighs 1 gram. By comparison, an adult sheep brain weighs 130-140 g (refer to Fig. 1 for comparisons). The large brain of sheep allows the use of in vivo measuring techniques of brain structure such as MRI [75-78]. The larger brain size also means that strategies devised for drug delivery directly into the brain in the sheep may translate well to humans. For the same reasons, sheep represent a good species as a 'follow-on' to early preclinical studies done in mice or rats, particularly for testing cell replacement approaches, or the delivery of gene therapy agents (Table 1 and Fig. 2).

Sheep brains are anatomically more similar to human brains than are the brains of mice. Sheep not only have gyrencephalic cerebral cortices but also more human-like subcortical structures than mice (Fig. 1). The sheep brain has a clearly identifiable separate caudate nucleus and putamen, and sheep thalamic nuclei are also more comparable to the human than those of the mouse. Furthermore, the GPi and substantia nigra in sheep are similar to those in non-human primates, both in size and functional organisation.

\section{SHEEP BEHAVIOUR}

Although sheep have a reputation for being stupid, this is probably undeserved, and based more on casual observation of flock behavior than it is on systematic testing. The fact that sheep have rarely been used for cognitive studies is more likely to be on the basis of practicality than ability. In fact, sheep exhibit all the behaviors that make rodents useful subjects for behavioral testing. They have good memories and are capable of learning and remembering new tasks [74, 80]. Sheep can perform some cognitive tasks that are extremely difficult to test in mice and rats, such as the intradimensional/extradimensional set shifting task that is considered to be a measure of executive function [74]. 
A Cell based models of mhtt

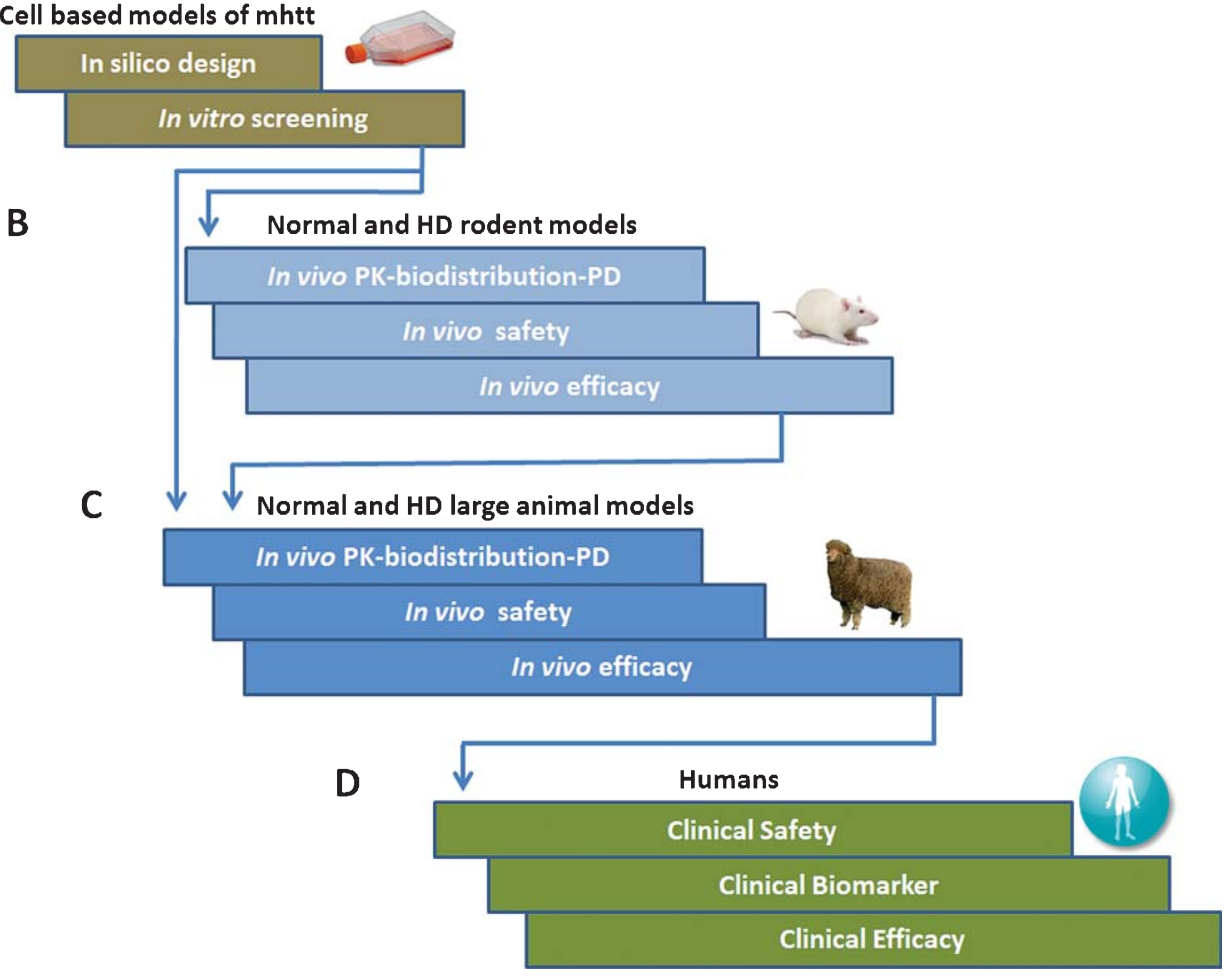

Fig. 2. A modified scheme for preclinical development of a gene based therapeutic for Huntington's disease. In silico design is typically followed by testing of candidate reagents in cell based models (a) for selecting those that are engaging the target of interest (i.e. the mutant HTT gene). Currently, gene therapies are tested for pharmacokinetic exposure, biodistribution in the CNS, specific activity (pharmacodynamics measures) and efficacy in normal and HD small animal models (b). A proposed inclusion (or eventual replacement for (b)) is the testing of gene therapy agents for PK, biodistribution, safety and efficacy using large animal models of HD (c) prior to proceeding for clinical testing in patients (d).

They also exhibit excellent facial (for references, see [72]) and olfactory recognition [79, 80].

\section{NEUROLOGICAL DISORDERS IN SHEEP}

Sheep develop progressive neurological diseases. Where these diseases are similar to those transmitted to humans (for example, new variant CJD), the progression of the disease in sheep is similar to that seen in human disease [81, 82]. Interestingly, it is emerging that there are a number of natural mutations found in sheep that cause neurological diseases with pathology similar to that seen in humans with similar mutations. For example, there are a number of sheep models of lysosomal storage diseases, such as Batten's disease [83] and Gaucher's disease [84]. Sheep also show human-like neurological symptoms in response to poisoning with neuroactive toxins. This raises the expectation that the HD mutation should cause a sheep form of HD with progression similar to that in humans.

\section{HUNTINGTON'S DISEASE TRANSGENIC SHEEP}

A number of lines of transgenic HD sheep have been developed in New Zealand and Australia [85]. These lines were made by pronuclear injection of a full length cDNA of human HTT carrying an uninterrupted 73 CAG repeat and driven by a human HTT gene promoter. From 127 Merino lambs born resulting from embryo transfers, six lambs (4 rams and 2 ewes) were identified as being transgenic for the human HTT transgene. The transgene integrated at a single genomic locus in 5 of the 6 transgenic founders but in multiple copies ranging from 2 to 14 . Whole genome sequencing and targeted capture of breakpoints with capillary sequencing has been performed on the HD transgenic sheep DNA to identify the chromosomal site of integration and in situ HTT transgene sequence [86]. The sequencing data showed that all of the founder HD sheep had evidence of transgene DNA shattering, leading to complex rearrangements of the DNA in the sheep chromosomes. However, intact full-length HTT trans- 
gene copies were evident in some of the transgenic founders including line $\mathrm{Go} / 5$ that has been the most well studied line. Based on skin fibroblast expression levels of mutant HTT mRNA and protein, founder $\mathrm{Go} / 5$ (OVT73, formerly known as the Kiwi line) was prioritized for breeding to F1 and further analyses. Its progeny express mutant human HTT mRNA and protein ubiquitously in the brain [87] and develop HTT aggregates and inclusions that are evident in various brain regions by 18 months in age (Patassini et al., personal communication). Jacobsen et al. [85] reported the dysregulation of DARPP-32 expression in the caudate and putamen of a single 7-month-old OvHD73 transgenic lamb, but this needs to be confirmed with larger number of animals. Although none of the founders showed any significant early pathology or overt phenotype, this was not unexpected, given that the mutation in the transgene is of a length that in humans would not be expected to manifest disease until late childhood. The oldest HD sheep (G1), currently 5 years old, are the subject of a comprehensive collaborative phenotyping initiative being conducted by Snell and colleagues (University of Auckland, NZ), Morton and colleagues (University of Cambridge, UK) and Bawden and colleagues (South Australia Research and Development Institute, Australia). The HD sheep as yet show no overt symptoms, however in-depth investigations are currently in progress. Only time will tell if the disease in these sheep progresses to a stage that they recapitulate phenotypic symptoms similar to human HD. Nevertheless, even without symptoms these HD sheep are a valuable resource. For example, because they carry a human transgene that is expressed at both an mRNA and a protein level, they could already be used for testing of gene therapy based reagents directed against human HTT (Fig. 2). In the context of the large animal brain, this would be useful for studying biodistribution and the relationship of pharmacokinetics (dose/efficacy) to the extent of HTT reduction in brain, as well as long-term safety (Fig. 2).

\section{DIFFICULTIES RELATING TO THE USE OF THE HUNTINGTON'S DISEASE TRANSGENIC SHEEP}

There are a significant number of hurdles to overcome before sheep can be used routinely as large animal models of HD. First, the sheep genome is not fully annotated. This creates difficulties in currently applying the full power of genomics technologies such as Affymetrix profiling and RNAseq for the analyses of genes and pathways that may be dysfunctional in any sheep model. Progress in this regard is being made in sequencing the sheep genome and establishing a transcriptome (see HTTp://www.animalgenome.org/sheep and ref [88]). Second, many behaviors that are easily and routinely assayed in rodents (locomotor function, cognitive function, anxiety) have never been quantified in sheep in a laboratory-like setting. Standard protocols for behavioral testing (such as those currently available for rodents) need to be established if they are to be used for cross-study comparisons. HD-relevant behaviors that would be useful to measure in HD sheep include cognitive, social and psychiatric function, but these behaviors are poorly characterized in sheep. Third, sheep are uniparous in breeding, and produce only a small number of lambs per year (1-3 per breeding ewe). Therefore a large number of breeding ewes is required to scale the breeding adequately for generation of the large numbers of animals that might be required for behavioral studies. Fourth, sheep are quadrupeds. This means that any motor symptoms are necessarily going to be different from that in bipedal humans; this is particularly important when considering the chorea that is characteristic of adult HD. Nevertheless, chorea is not the only motor symptom of HD, and many of the other abnormalities in motor function seen in HD (rigidity, dysphagia, bradykinesia) have been identified in large quadrupeds [89]. Finally, sheep are ruminants. Rumination is a distinct disadvantage both for oral drug delivery and the study of the digestive system. But for translational drug discovery research, the great strength of a large animal model for HD lies with investigation of therapies aimed at direct administration to the large brain as opposed to investigation of small molecules given by oral dosing. Therefore sheep rumination is not likely to present an insurmountable hurdle to testing drug delivery.

\section{PIGS AS MODELS OF HUNTINGTON'S DISEASE}

As with sheep, there are considerable advantages for using the pig as a laboratory species, especially with regards to the similarities between human and porcine brain structure and function. Pigs have brains similar in size and structure to sheep (Fig. 1). They have relatively long lifespans (12-15 years), and so they should be useful for studying early changes in neurodegenerative diseases, with potentially long prodromal periods (Table 1). Physiologically, pigs make a 'close to ideal' model for humans. All of their body systems are very 
similar to humans, including their digestive systems. As such, they have been widely used as large animal models of reproductive biology, respiratory and cardiovascular physiology (see ref [90] for review). Pigs are domesticated, but remain relatively outbred. In the wild, female pigs live in small groups; males are solitary and intact males cannot be housed together. But castrated males do not pose this problem, and pigs are routinely raised in large numbers for the food industry, so husbandry methods are well established. Pigs raised for food are rarely kept in natural groups outdoors, so there are issues of impoverishment of environment associated with 'laboratory' animals. But they are economical and practical to use as research subjects. There has been substantial progress in sequencing the porcine genome [91-94] making application of gene profiling studies such as RNAseq useful for mapping gene and network dysregulation in an HD minipig. Furthermore, genetic manipulation techniques that allow for transgenesis and homologous recombination are well advanced in minipig strains [95-97] such that mutant HTT could be engineered in minipig in multiple ways.

\section{HUNTINGTON'S DISEASE MINIPIGS}

Yang et al. [98] reported on the successful generation of transgenic HD minipigs using somatic cell nuclear transfer technology. Two transgenes were constructed, a human HTT N208-105Q-ECFP and an N208-160Q-ECFP each where expression was driven by the strong constitutive chicken beta-actin promoter with a cytomegalovirus enhancer. Reconstruction of porcine embryos after injection of the N208-160QECFP transgene did not result in any live births, suggesting that this HTT fragment harboring a very high CAG repeat length resulted in embryo toxicity. In contrast, there were five live births carrying the N208-105Q-ECFP transgene. Although transgenic piglets appeared normal at birth, three of the piglets died within 3 days, and a fourth lived for only 25 days. The fifth founder was still viable at time of publication. This animal showed the lowest expression of the mutant HTT fragment of all the transgenic offspring, which suggests that high levels of mutant HTT expression contributed to an early death phenotype in the other piglets. Histological analyses of brain sections from the piglets that died early showed evidence of neuronal EM48 antibody immunoreactivity, verifying presence of mutant HTT. Neuronal cells positively stained for mutant HTT also showed evidence of fragmented DNA, a sign for cell apoptosis.
A new HD minipig model has been developed by Motlik and colleagues at the Institute of Animal Physiology and Genetics in the Czech Republic (Baxa et al., 2013, this issue). In this line, lentiviral based transgenes were constructed carrying a human minimal HTT gene promoter driving either a 548 amino acid or full length (3144 amino acid) human HTT cDNA containing 145 repeats of a mixed CAGCAA sequence. Founders for each the 548 amino acid fragment and the full length HTT transgenes were generated. The 548 amino acid founder has been bred successfully out to the G3 generation. The oldest of these HD minipigs is approximately 3 years at the time of writing, and do not show overt disease symptoms. Thus, as with the HD sheep, they have great promise as useful HD large animals, potentially modeling the slow and progressive nature of $\mathrm{HD}$, although this promise has not yet been fulfilled. Evidence of mutant HTT expression in brain has been shown along with some specific biochemical phenotypes including reduced DARPP-32 expression in the striatum of 16 month old HD minipigs as well as reduced sperm cell motility and oocyte penetration, an indication that the mutant HTT is having effects at early ages. These HD minipigs are the subject of a comprehensive phenotyping initiative being conducted by Reilmann and colleagues (University of Munster) where the plan is to use outcome measures informed by human HD observational studies (TRACK-HD) in premanifest patients $[99,100]$.

\section{RELATIVE MERITS OF SHEEP AND PIGS AS MODELS OF HD}

With both pigs and sheep, the big advantage for long-term studies is the wide experience of traditional agriculture that increases the feasibility of long-term studies. In some respects, in particular, pigs have clear advantages over sheep. While their gestation times are similar (113-115 days), pigs are multiparous and produce large litters (of up to 10 piglets). Breeding sows can have 2 litters a year. This is an obvious advantage where generation of large numbers of animals is desired. Pigs are omnivores, and have a digestive system very similar to humans [90]. This contrasts favourably with sheep, which are ruminants and obligate herbivores.

But there are also disadvantages of pigs compared with sheep. Adult males do not live in social groups and uncastrated boars need to be housed individually. Female pigs live in groups, but among animals in the same litter a strong social hierarchy is established 
within a few days after birth and persists throughout their lifetimes, which is likely to be an important factor in social behavioural testing. Both pigs and sheep are docile and pose relatively little risk to the investigator. When there is a risk however, this is likely to be greater for pigs than for sheep, since the natural instinct of a sheep in a threatening situation is to flee, whereas that of a pig is to challenge. Body size may also turn out to be an issue. Pigs continue to grow throughout their lives, and most farm pigs grow too large to be practical for experimental use. There are several miniature and micro-pig breeds that have become successful laboratory models [90]. Micropigs will not be considered further as models for HD, since any advantage they have in small body size is lost because their brains are correspondingly smaller as well. Minipigs are likely to be the species of choice, because they are already relatively well characterised. It should also be noted however that 'mini' is a relative term. Minipigs are small compared to landrace pigs that can achieve body sizes of $400-600$ pounds by 2 years of age. But the Tibetan and Libechov minipigs that have been used to make the HD models as described above are not small animals -indeed, a minipig can grow substantially, and could weigh up to 250 pounds or more as an adult, depending on its genetic background. This large body size, coupled with the associated strength will make conducting behavioural testing with these animals an interesting challenge.

The feasibility of stereotactically-guided delivery of drugs into the brain has been found to be good for both pigs [76] and sheep [77]. Sheep have an advantage over pigs where implanted brain devices are concerned. Pigs have large skull sinuses that preclude long term implants. (Long term EEG studies have not been successfully achieved in pigs for this reason). Sheep have a different skull anatomy that makes longterm recordings from sheep brain feasible. Indeed, we have recorded EEGs from sheep brains for up to a year using skull electrodes (AJM, unpublished data).

Both pigs and sheep are easily anaesthetized and amenable to in vivo imaging modalities applied in humans. Imaging has been conducted much more widely in pigs than in sheep. MRI, fMRI and nuclear magnetic resonance spectroscopy studies have all been done in pigs [101-103] as has PET [104-106]. Nevertheless, both MRI and CT scanning have been conducted successfully in sheep ([77, 107]; and AJM, unpublished data).

Pigs are generally considered to be 'smarter' than sheep, although direct evidence for this is lacking. Indeed, neither species has been used routinely in the laboratory for cognitive testing. This is a hurdle to the use of both species for behavioral studies, since there are no well-established tests for systematically measuring cognitive function in either pigs or sheep. In contrast, cognitive testing is well established in monkeys, an advantage for modeling in non-human primates.

\section{LARGE ANIMAL MODELS OF HD: WHERE ARE WE HEADING?}

We recognize that no single animal model can fulfill all of the requirements needed to address the many remaining questions in HD research and development. We also recognize that it is unlikely that the power of genetics, as has been used in lower organism and mouse models of HD to uncover developmental and cell biological consequences of mutant HTT, could be applied as effectively to monkey, sheep or minipig models. Nevertheless, large HD animal models are already proving to be interesting supplements to the arsenal of lower organism and small animal models of HD that have been used to such good effect over the last two decades. For example, the published work reported in the transgenic rhesus macaque represented a first significant leap forward as a proof of concept that a fragment human HTT transgene with expanded $\mathrm{CAG}$ repeats results in a severe pathophysiology. Histological analyses of the brains from these monkeys showed classical nuclear and neuropil aggregates that are similar to the histopathology seen in rodents. Some of the arguments about the relevance of aggregates in rodents to primate disease should now be laid to rest. The data from transgenic HTT fragment minipigs extended the findings from the transgenic non- human primates showing that high level expression of a fragment of the human gene recapitulates a histological mutant HTT phenotype and results in early behavioral deficits.

Renewed efforts are underway to make models of transgenic non-human primates, minipigs as well as full-length transgenic HD sheep in which disease develops more gradually. These long-lived HD animal models therefore hold great promise for recapitulating the slow and progressive nature of HD and providing an invaluable resource for HD research and drug development. It will be important to include them in preclinical testing designs, especially for gene therapies as data obtained here will be valuable for predicting biodistribution, safety and efficacy in HD patients (Fig. 2).

The work described in this review represents significant steps toward modeling HD in large animals. 
However, there is one limitation of all of the large animal HD models described here. They are all transgenic thus each model expresses two copies of their own normal Htt genes as well as the extra copies of HTT introduced via a transgene. None of these models recapitulates HD at the genetic level, where there is typically one normal allele and one mutant allele. The potential impact of overexpressing total HTT in mouse models is recognized [108, 109], but not well understood. Nevertheless, it is likely to play a role in the progression and manifestation of the disease, and remains a caveat. In an effort to alleviate this problem in part work is underway at Exemplar Genetics (Sioux City, IA) to generate a knock-in model of HD in the minipig.

New large animal models of HD are being developed by multiple groups, and their characterization is progressing apace. Importantly these large animal models are being studied for disease phenotypes using sensitive measures that should be highly translatable to the human condition including MRI, and PET imaging, EEG, electrophysiology, molecular analyses including RNAseq, in addition to tests looking at motor, and cognitive function. With current efforts from groups working on transgenic HD non-human primates at Emory Yerkes Primates Center, USA, the viral-based mHTT expression in non-human primates at the Oregon National Primate Research Center, USA, the transgenic HD sheep at SARDI in Australia and transgenic HD minipigs in the Czech Republic, there is good likelihood that large genetic HD animal models will eventuate, that can be used not only to study premanifest and manifest disease, but also to test delivery of gene-targeted therapies in a large brain context.

This review has discussed a new direction for modeling of disease in animals. But alongside the new models comes new challenges. None of the animal models discussed above are ready to be used by the research community. However, if they are to be used optimally once they become available, the HD research community will need to take a new approach to some practical aspects of preclinical research. Currently, most experimental programs depend on an individual researcher's personal interests, and their ability to apply successfully for research funding. The design of all experiments requires careful planning, but experiments that might last 5 or more years require not only careful planning, but also critical evaluation of scientific priorities. Research funding will also need to work to a different model. With grant cycles rarely exceeding 3 years, studies that might take 5-10 years are currently not feasible, and will not be possible with existing models of funding. Finally, given that large animals have requirements for space that are not available in most city-based universities, unless a creative approach is taken to sharing animals, access for the average investigator to large animal models of HD will be limited. Thus the valuable resource, that large animal models of HD should become, will be underused. Long-term collaborations, as well as pooling of resources, will become much more important for experiments using large animal models than they currently are with rodents. Although large animals will necessarily remain the subjects of 'boutique' studies, strenuous efforts should be made to develop a mechanism whereby researchers who do not have the appropriate facilities to set up their own studies can negotiate access to animals for their experiments. Neither the mechanism nor funding for this type of long-term collaborative research currently exists.

\section{ACKNOWLEDGMENTS}

We thank Simon Noble from CHDI for his thoughtful critiques of this review and the University of Wisconsin and Michigan State Comparative Mammalian Brain Collection for the use of the images in Fig. 1.

\section{CONFLICT OF INTEREST}

The authors have no conflicts of interest.

\section{REFERENCES}

[1] The Huntington's Disease Collaborative Research Group. A novel gene containing a trinucleotide repeat that is expanded and unstable on Huntington's disease chromosomes. Cell. 1993;72:971

[2] Strong TV, Tagle DA, Valdes JM, Elmer LW, Boehm K, Swaroop M, Kaatz KW, Collins FS, Albin RL. Widespread expression of the human and rat Huntington's disease gene in brain and nonneural tissues. Nat Genet. 1993;5(3):259.

[3] Sharp AH, Loev SJ, Schilling G, Li SH, Li XJ, Bao J, Wagster MV, Kotzuk JA, Steiner JP, Lo A, et al. Widespread expression of Huntington's disease gene (IT15) protein product. Neuron. 1995;14(5):1065.

[4] Gusella JF, MacDonald ME. Huntington's disease: CAG genetics expands neurobiology. Curr Opin Neurobiol. 1995;5(5):656.

[5] Zoghbi HY, Orr HT. Glutamine repeats and neurodegeneration. Annu Rev Neurosci. 2000;23:217.

[6] Moseley ML, Zu T, Ikeda Y, Gao W, Mosemiller AK, Daughters RS, Chen G, Weatherspoon MR, Clark HB, Ebner TJ, Day JW, Ranum LP. Bidirectional expression of CUG and CAG expansion transcripts and intranuclear polyglutamine inclusions in spinocerebellar ataxia type 8 . Nat Genet. 2006;38(7):758. 
[7] Bañez-Coronel M, Porta S, Kagerbauer B, Mateu-Huertas E, Pantano L, Ferrer I, Guzmán M, Estivill X, Martí E. A pathogenic mechanism in Huntington's disease involves small CAG-repeated RNAs with neurotoxic activity. PLoS Genet. 2012;8(2):e1002481.

[8] Pearson CE. Repeat associated non-ATG translation initiation: One DNA, two transcripts, seven reading frames, potentially nine toxic entities! PLoS Genet. 2011;7(3): e1002018.

[9] Wojciechowska M, Krzyzosiak WJ. CAG repeat RNA as an auxiliary toxic agent in polyglutamine disorders. RNA Biol. 2011;8(4):565.

[10] Smith MM, Mills JA, Epping EA, Westervelt HJ, Paulsen JS; PREDICT-HD Investigators of the Huntington Study Group. Depressive symptom severity is related to poorer cognitive performance in prodromal Huntington disease. Neuropsychology. 2012;26(5):664.

[11] Harrington DL, Smith MM, Zhang Y, Carlozzi NE, Paulsen JS; PREDICT-HD Investigators of the Huntington Study Group. Cognitive domains that predict time to diagnosis in prodromal Huntington disease. J Neurol Neurosurg Psychiatry. 2012;83(6):612.

[12] Schulte J, Littleton JT. The biological function of the Huntingtin protein and its relevance to Huntington's Disease pathology. Curr Trends Neurol. 2011;5:65.

[13] Raymond LA, André VM, Cepeda C, Gladding CM, Milnerwood AJ, Levine MS. Pathophysiology of Huntington's disease: Time-dependent alterations in synaptic and receptor function. Neuroscience. 2011;198:252.

[14] Jones L, Hughes A. Pathogenic mechanisms in Huntington's disease. Int Rev Neurobiol. 2011;98:373.

[15] Reiner A, Dragatsis I, Dietrich P. Genetics and neuropathology of Huntington's disease. Int Rev Neurobiol. 2011:98:325.

[16] Shoulson I, Young AB. Milestones in Huntington disease. Mov Disord. 2011;26(6):1127.

[17] Morton AJ. Circadian and sleep disorder in Huntington's disease. Exp Neurol. 2012. (Epub ahead of print)

[18] Ha AD, Fung VS. Huntington's disease. Curr Opin Neurol. 2012;25(4):491.

[19] Zheng Z, Diamond MI. Huntington disease and the huntingtin protein. Prog Mol Biol Transl Sci. 2012;107:189.

[20] van den Bogaard S, Dumas E, van der Grond J, van Buchem M, Roos R. MRI biomarkers in Huntington's disease. Front Biosci (Elite Ed). 2012;4:1910.

[21] Shang H, Danek A, Landwehrmeyer B, Burgunder JM. Huntington's disease: New aspects on phenotype and genotype. Parkinsonism Relat Disord. 2012;18(Suppl 1): S107.

[22] Brooks SP, Jones L, Dunnett SB. Comparative analysis of pathology and behavioural phenotypes in mouse models of Huntington's disease. Brain Res Bull. 2012;88(2-3):81.

[23] Mestre TA, Ferreira JJ. An evidence-based approach in the treatment of Huntington's disease. Parkinsonism Relat Disord. 2012;18(4):316

[24] Venuto CS, McGarry A, Ma Q, Kieburtz K. Pharmacologic approaches to the treatment of Huntington's disease. Mov Disord. 2012;27(1):31.

[25] Ross CA, Tabrizi SJ. Huntington's disease: From molecular pathogenesis to clinical treatment. Lancet Neurol. 2011:10(1):83.

[26] Munoz-Sanjuan I, Bates GP. The importance of integrating basic and clinical research toward the development of new therapies for Huntington disease. J Clin Invest. 2011;121(2):476
[27] Sah DW, Aronin N. Oligonucleotide therapeutic approaches for Huntington disease. J Clin Invest. 2011;121(2):500.

[28] Johnson CD, Davidson BL. Huntington's disease: Progress toward effective disease-modifying treatments and a cure. Hum Mol Genet. 2010;19(R1):R98-R102

[29] McBride JL, Pitzer MR, Boudreau RL, Dufour B, Hobbs T, Ojeda SR, Davidson BL. Preclinical safety of RNAimediated HTT suppression in the rhesus macaque as a potential therapy for Huntington's disease. Mol Ther. 2011;19(12):2152.

[30] Mangiarini L, Sathasivam K, Seller M, Cozens B, Harper A, Hetherington C, Lawton M, Trottier Y, Lehrach H, Davies SW, Bates GP. Exon 1 of the HD gene with an expanded CAG repeat is sufficient to cause a progressive neurological phenotype in transgenic mice. Cell. 1996;87(3):493.

[31] Schilling G, Becher MW, Sharp AH, Jinnah HA, Duan K, Kotzuk JA, Slunt HH, Ratovitski T, Cooper JK, Jenkins NA, Copeland NG, Price DL, Ross CA, Borchelt DR. Intranuclear inclusions and neuritic aggregates in transgenic mice expressing a mutant $\mathrm{N}$-terminal fragment of huntingtin. Hum Mol Genet. 1999;8(3):397. Erratum in: Hum Mol Genet. 1999;8(5):943.

[32] de Almeida LP, Ross CA, Zala D, Aebischer P, Déglon $\mathrm{N}$. Lentiviral-mediated delivery of mutant huntingtin in the striatum of rats induces a selective neuropathology modulated by polyglutamine repeat size, huntingtin expression levels, and protein length. J Neurosci. 2002;22(9):3473.

[33] Slow EJ, van Raamsdonk J, Rogers D, Coleman SH, Graham RK, Deng Y, Oh R, Bissada N, Hossain SM, Yang YZ, Li XJ, Simpson EM, Gutekunst CA, Leavitt BR, Hayden MR. Selective striatal neuronal loss in a YAC128 mouse model of Huntington disease. Hum Mol Genet. 2003:12(13); 1555.

[34] Gray M, Shirasaki DI, Cepeda C, André VM, Wilburn B, Lu XH, Tao J, Yamazaki I, Li SH, Sun YE, Li XJ, Levine MS, Yang XW. Full-length human mutant huntingtin with a stable polyglutamine repeat can elicit progressive and selective neuropathogenesis in BACHD mice. J Neurosci. 2008;28(24):6182.

[35] von Hörsten S, Schmitt I, Nguyen HP, Holzmann C, Schmidt T, Walther T, Bader M, Pabst R, Kobbe P, Krotova J, Stiller D, Kask A, Vaarmann A, Rathke-Hartlieb S, Schulz JB, Grasshoff U, Bauer I, Vieira-Saecker AM, Paul M, Jones L, Lindenberg KS, Landwehrmeyer B, Bauer A, Li XJ, Riess $\mathrm{O}$. Transgenic rat model of Huntington's disease. Hum Mol Genet. 2003;12(6):617.

[36] Yu-Taeger L, Petrasch-Parwez E, Osmand AP, Redensek A, Metzger S, Clemens LE, Park L, Howland D, Calaminus C, Gu X, Pichler B, Yang XW, Riess O, Nguyen HP. A Novel BACHD Transgenic Rat Exhibits Characteristic Neuropathological Features of Huntington Disease. J Neurosci. 2012;32(44): 15426.

[37] Wheeler VC, Auerbach W, White JK, Srinidhi J, Auerbach A, Ryan A, Duyao MP, Vrbanac V, Weaver M, Gusella JF, Joyner AL, MacDonald ME. A novel BACHD transgenic rat exhibits characteristic neuropathological features of huntington disease. Hum Mol Genet. 1999;8(1):115.

[38] Lin CH, Tallaksen-Greene S, Chien WM, Cearley JA, Jackson WS, Crouse AB, Ren S, Li XJ, Albin RL, Detloff PJ. Neurological abnormalities in a knock-in mouse model of Huntington's disease. Hum Mol Genet. 2001;10(2):137.

[39] Menalled LB, Sison JD, Dragatsis I, Zeitlin S, Chesselet MF Time course of early motor and neuropathological anomalies in a knock-in mouse model of Huntington's disease with 140 CAG repeats. J Comp Neurol. 2003;465(1):11. 
[40] Menalled LB, Kudwa AE, Miller S, Fitzpatrick J, WatsonJohnson J, Keating N, Ruiz M, Mushlin R, Alosio W, McConnell K, Connor D, Murphy C, Oakeshott S, Kwan M, Beltran J, Ghavami A, Brunner D, Park LC, Ramboz S, Howland D. Comprehensive behavioral and molecular characterization of a new knock-in mouse model of huntington's disease: zQ175. PLoS One. 2012;7(12):e49838

[41] Heng MY, Duong DK, Albin RL, Tallaksen-Greene SJ, Hunter JM, Lesort MJ, Osmand A, Paulson HL, Detloff PJ. Early autophagic response in a novel knock-in model of Huntington disease. Hum Mol Genet. 2010;19(19): 3702.

[42] Sathasivam K, Neueder A, Gipson TA, Landles C, Benjamin AC, Bondulich MK, Smith DL, Faull RL, Roos RA, Howland D, Detloff PJ, Housman DE, Bates GP. Aberrant splicing of HTT generates the pathogenic exon 1 protein in Huntington disease. Proc Natl Acad Sci U S A. 2013;110(6):2366-70.

[43] Bowles KR, Brooks SP, Dunnett SB, Jones L. Gene expression and behaviour in mouse models of HD. Brain Res Bull. 2012;88(2-3):276.

[44] Davies SW, Turmaine M, Cozens BA, DiFiglia M, Sharp AH, Ross CA, Scherzinger E, Wanker EE, Mangiarini L, Bates GP. Formation of neuronal intranuclear inclusions underlies the neurological dysfunction in mice transgenic for the HD mutation. Cell. 1997;90(3):537.

[45] Ransome MI, Renoir T, Hannan AJ. Hippocampal neurogenesis, cognitive deficits and affective disorder in Huntington's disease. Neural Plast. 2012;2012:874387.

[46] Ramaswamy S, McBride JL, Kordower JH. Animal models of Huntington's disease. ILAR J. 2007;48(4):356.

[47] Scahill RI, Hobbs NZ, Say MJ, Bechtel N, Henley SM, Hyare H, Langbehn DR, Jones R, Leavitt BR, Roos RA, Durr A, Johnson H, Lehéricy S, Craufurd D, Kennard C, Hicks SL, Stout JC, Reilmann R, Tabrizi SJ; the TRACKHD investigators. Clinical impairment in premanifest and early Huntington's disease is associated with regionally specific atrophy. Hum Brain Mapp. 2013;34(3):519.

[48] Wolf RC, Sambataro F, Vasic N, Wolf ND, Thomann PA, Saft C, Landwehrmeyer GB, Orth M. Default-mode network changes in preclinical Huntington's disease. Exp Neurol. 2012;237(1):191.

[49] Novak MJ, Warren JD, Henley SM, Draganski B, Frackowiak RS, Tabrizi SJ. Altered brain mechanisms of emotion processing in pre-manifest Huntington's disease. Brain 2012;135(Pt 4):1165.

[50] Delmaire C, Dumas EM, Sharman MA, van den Bogaard SJ, Valabregue R, Jauffret C, Justo D, Reilmann R, Stout JC, Craufurd D, Tabrizi SJ, Roos RA, Durr A, Lehéricy $\mathrm{S}$. The structural correlates of functional deficits in early huntington's disease. Hum Brain Mapp. 2012; doi: 10.1002/hbm.22055 (Epub ahead of print)

[51] Paulsen JS, Langbehn DR, Stout JC, Aylward E, Ross CA, Nance M, Guttman M, Johnson S, MacDonald M, Beglinger LJ, Duff K, Kayson E, Biglan K, Shoulson I, Oakes D, Hayden M. Predict-HD Investigators and Coordinators of the Huntington Study Group. Detection of Huntington's disease decades before diagnosis: The Predict-HD study. J Neurol Neurosurg Psychiatry. 2008;79(8):874.

[52] Orth M, Schippling S, Schneider SA, Bhatia KP, Talelli P, Tabrizi SJ, Rothwell JC. Abnormal motor cortex plasticity in premanifest and very early manifest Huntington disease. J Neurol Neurosurg Psychiatry. 2010;81(3):267.

[53] Wadman, M. Animal rights: Chimpanzee research on trial. Nature. 2011;474(7351):268.
[54] Krasemann S, Sikorska B, Liberski PP, Glatzel M. Nonhuman primates in prion research. Folia Neuropathol. 2012;50(1):57.

[55] Löw K, Aebischer P. Use of viral vectors to create animal models for Parkinson's disease. Neurobiol Dis. 2012;48(2):189.

[56] Fernagut PO, Tison F. Animal models of multiple system atrophy. Neuroscience. 2012;211:77.

[57] Webster SJ, Wilson CA, Lee CH, Mohler EG, Terry AV $\mathrm{Jr}$, Buccafusco JJ. The acute effects of dimebolin, a potential Alzheimer's disease treatment, on working memory in rhesus monkeys. Br J Pharmacol. 2011;164(3):970.

[58] Porter JN, Olsen AS, Gurnsey K, Dugan BP, Jedema HP, Bradberry CW. Chronic cocaine self-administration in rhesus monkeys: Impact on associative learning, cognitive control, and working memory. J Neurosci. 2011;31(13): 4926.

[59] Uslaner JM, Eddins D, Puri V, Cannon CE, Sutcliffe J, Chew CS, Pearson M, Vivian JA, Chang RK, Ray WJ, Kuduk SD, Wittmann M. The muscarinic M1 receptor positive allosteric modulator PQCA improves cognitive measures in rat, cynomolgus macaque, and rhesus macaque. Psychopharmacology (Berl). 2013;225(1):21.

[60] Burns LH, Pakzaban P, Deacon TW, Brownell AL, Tatter SB, Jenkins BG, Isacson O. Selective putaminal excitotoxic lesions in non-human primates model the movement disorder of Huntington disease. Neuroscience. 1995;64(4): 1007.

[61] Kendall AL, David F, Rayment G, Torres EM, Annett LE, Dunnett SB. The influence of excitotoxic basal ganglia lesions on motor performance in the common marmoset. Brain. 2000;123(Pt 7):1442.

[62] Palfi S, Brouillet E, Jarraya B, Bloch J, Jan C, Shin M, Condé F, Li XJ, Aebischer P, Hantraye P, Déglon N. Expression of mutated huntingtin fragment in the putamen is sufficient to produce abnormal movement in non-human primates. Mol Ther. 2007;15(8): 1444 .

[63] Yang SH, Cheng PH, Banta H, Piotrowska-Nitsche K, Yang JJ, Cheng EC, Snyder B, Larkin K, Liu J, Orkin J, Fang ZH, Smith Y, Bachevalier J, Zola SM, Li SH, Li XJ, Chan AW. Towards a transgenic model of Huntington's disease in a non-human primate. Nature. 2008;453(7197):921.

[64] Chan AW, Yang SH. Generation of transgenic monkeys with human inherited genetic disease. Methods. 2009;49(1):7884

[65] Morton AJ, Lagan MA, Skepper JN, Dunnett SB. Progressive formation of inclusions in the striatum and hippocampus of mice transgenic for the human Huntington's disease mutation. J Neurocytol. 2000;29(9):679.

[66] Wang CE, Tydlacka S, Orr AL, Yang SH, Graham RK, Hayden MR, Li S, Chan AW, Li XJ. Accumulation of N-terminal mutant huntingtin in mouse and monkey models implicated as a pathogenic mechanism in Huntington's disease. Hum Mol Genet. 2008;17(17):2738-51

[67] Putkhao K, Kocerha J, Cho IK, Yang J, Parnpai R, Chan AW. Pathogenic Cellular Phenotypes are Germline Transmissible in a Transgenic Primate Model of Huntington's Disease. Stem Cells Dev. 2013. (Epub ahead of print)

[68] Laowtammathron C, Cheng ECh, Cheng PH, Snyder BR, Yang SH, Johnson Z, Lorthongpanich C, Kuo HC, Parnpai $\mathrm{R}$, Chan AW Monkey hybrid stem cells develop cellular features of Huntington's disease. BMC Cell Biol. 2010;11:12.

[69] Chan AW, Cheng PH, Neumann A, Yang JJ. Reprogramming Huntington monkey skin cells into pluripotent stem cells. Cell Reprogram. 2010;12(5):509-17 
[70] Sparman ML, Tachibana M, Mitalipov SM. Cloning of nonhuman primates: The road "less traveled by". Int J Dev Biol. 2010;54(11-12):1671.

[71] Clarke IJ. Control of GnRH secretion: One step back. Front Neuroendocrinol. 2011;32(3):367.

[72] Kendrick KM, da Costa AP, Leigh AE, Hinton MR, Peirce JW. Sheep don't forget a face. Nature. 2001;414(6860):165. Erratum in: Nature. 2007;447(7142):346.

[73] Tate AJ, Fischer H, Leigh AE, Kendrick KM. Behavioural and neurophysiological evidence for face identity and face emotion processing in animals. Philos Trans R Soc Lond B Biol Sci. 2006;361(1476):2155.

[74] Morton AJ, Avanzo L. Executive decision-making in the domestic sheep. PLoS One. 2011;31:6(1):e15752.

[75] Opdam HI, Federico P, Jackson GD, Buchanan J, Abbott DF, Fabinyi GC, Syngeniotis A, Vosmansky M, Archer JS, Wellard RM, Bellomo R. A sheep model for the study of focal epilepsy with concurrent intracranial EEG and functional MRI. Epilepsia. 2002;43(8):779.

[76] Bjarkam CR, Cancian G, Glud AN, Ettrup KS, Jørgensen RL, Sørensen JC. MRI-guided stereotaxic targeting in pigs based on a stereotaxic localizer box fitted with an isocentric frame and use of SurgiPlan computer-planning software. J Neurosci Methods. 2009;183(2):119.

[77] van der Bom IM, Moser RP, Gao G, Sena-Esteves M, Aronin N, Gounis MJ. Frameless multimodal image guidance of localized convection-enhanced delivery of therapeutics in the brain. J Neurointerv Surg. 2013;5(1):69.

[78] Wells AJ, Vink R, Blumbergs PC, Brophy BP, Helps SC, Knox SJ, Turner RJ. A surgical model of permanent and transient middle cerebral artery stroke in the sheep. PLoS One. 2012;7(7):e42157.

[79] Sánchez-Andrade G, James BM, Kendrick KM. Neural encoding of olfactory recognition memory. J Reprod Dev. 2005;51(5):547.

[80] Nowak R, Keller M, Lévy F. Mother-young relationships in sheep: A model for a multidisciplinary approach of the study of attachment in mammals. J Neuroendocrinol. 2011;23(11):1042.

[81] Hunter N, Goldmann W, Marshall E, O’Neill G. Sheep and goats: Natural and experimental TSEs and factors influencing incidence of disease. Arch Virol Suppl. 2000;16:181.

[82] Mallucci G, Collinge J. Update on Creutzfeldt-Jakob disease. Curr Opin Neurol. 2004;17(6):641.

[83] Palmer D, Tammen I, Drögemüller C, Johnson G, Katz M, Lingaas F. Large Animal Models. In The Neuronal Ceroid LIPOFUSCINOSES (Batten Disease) 2011; pp. 284-320. New York, US: Oxford University Press.

[84] Karageorgos L, Lancaster MJ, Nimmo JS, Hopwood JJ. Gaucher disease in sheep. J Inherit Metab Dis. 2011; 34(1):209.

[85] Jacobsen JC, Bawden CS, Rudiger SR, McLaughlan CJ, Reid SJ, Waldvogel HJ, MacDonald ME, Gusella JF, Walker SK, Kelly JM, Webb GC, Faull RL, Rees MI, Snell RG. An ovine transgenic Huntington's disease model. Hum Mol Genet. 2010;19(10):1873.

[86] Chiang C, Jacobsen JC, Ernst C, Hanscom C, Heilbut A, Blumenthal I, Mills RE, Kirby A, Lindgren AM, Rudiger SR, McLaughlan CJ, Bawden CS, Reid SJ, Faull RL, Snell RG, Hall IM, Shen Y, Ohsumi TK, Borowsky ML, Daly MJ, Lee C, Morton CC, MacDonald ME, Gusella JF, Talkowski ME. Complex reorganization and predominant non-homologous repair following chromosomal breakage in karyotypically balanced germline rearrangements and transgenic integration. Nat Genet. 2012;44(4):390.
[87] Reid SJ, Handley RR, Patassini S, Rudiger SR, Keynes, P, McLaughhlan, CJ, Waldvogel, HJ, Jacobsen, JC, Macdonald, ME, Gusella, JF, Morton, AJ, Bawden, CS, Faull, RLM, Snell, RG. Clinical Genetics Special Issue: Clinical Genetics Special Issue: Abstracts for the 2011 World Congress on Huntington's Disease, 11-14 September 2011, Melbourne, Australia, September 2011, Volume 80, Issue Supplement s1; Abstract 144.

[88] Handley, RR, Reid, SJ, Tsai, P, Faull, RLM, Snell, RG. Clinical Genetics Special Issue: Abstracts for the 2011 World Congress on Huntington's Disease, 11-14 September 2011, Melbourne, Australia, September 2011, Volume 80, Issue Supplement s1; Abstract 112.

[89] Bourke CA, Bunker EC, Reece RI, Whittaker SJ. Cerebellar ataxia in sheep grazing pastures infested with Romulea rosea (onion grass or Guildford grass). Aust Vet J. 2008;86(9):354.

[90] Vodicka P, Smetana K Jr, Dvoránková B, Emerick T, Xu YZ, Ourednik J, Ourednik V, Motlík J. The miniature pig as an animal model in biomedical research. Ann N Y Acad Sci. 2005;1049:161.

[91] Archibald AL, Bolund L, Churcher C, Fredholm M, Groenen MA, Harlizius B, et al. Pig genome sequenceanalysis and publication strategy. BMC Genomics. 2010;11: 438

[92] Jiang Z, Rothschild MF. Swine genome science comes of age. International Journal of Biological Sciences. 2007;3(3):129.

[93] Jorgensen FG, Hobolth A, Hornshoj H, Bendixen C, Fredholm M, Schierup MH. Comparative analysis of protein coding sequences from human, mouse and the domesticated pig. BMC Biology. 2005;3:2.

[94] Wernersson R, Schierup MH, Jorgensen FG, Gorodkin J, Panitz F, Staerfeldt $\mathrm{HH}$, et al. Pigs in sequence space: A $0.66 \mathrm{X}$ coverage pig genome survey based on shotgun sequencing. BMC Genomics. 2005;6:70.

[95] Hofmann A, Kessler B, Ewerling S, Weppert M, Vogg B, Ludwig H, Stojkovic M, Boelhauve M, Brem G, Wolf E, Pfeifer A. Efficient transgenesis in farm animals by lentiviral vectors. EMBO Rep. 2003;4(11):1054

[96] Nagashima H, Fujimura T, Takahagi Y, Kurome M, Wako N, Ochiai T, Esaki R, Kano K, Saito S, Okabe M, Murakami H. Development of efficient strategies for the production of genetically modified pigs. Theriogenology. 2003;59(1): 95.

[97] Kurome M, Ueda H, Tomii R, Naruse K, Nagashima H. Production of transgenic-clone pigs by the combination of ICSI-mediated gene transfer with somatic cell nuclear transfer. Transgenic Res. 2006;15(2):229.

[98] Yang D, Wang CE, Zhao B, Li W, Ouyang Z, Liu Z, Yang H, Fan P, O’Neill A, Gu W, Yi H, Li S, Lai L, Li XJ. Expression of Huntington's disease protein results in apoptotic neurons in the brains of cloned transgenic pigs. Hum Mol Genet. 2010;19(20):3983.

[99] Tabrizi SJ, Reilmann R, Roos RA, Durr A, Leavitt B, Owen G, Jones R, Johnson H, Craufurd D, Hicks SL, Kennard C, Landwehrmeyer B, Stout JC, Borowsky B, Scahill RI, Frost C, Langbehn DR. TRACK-HD investigators. Potential endpoints for clinical trials in premanifest and early Huntington's disease in the TRACK-HD study: Analysis of 24 month observational data. Lancet Neurol. 2012;11(1):42.

[100] Tabrizi SJ, Langbehn DR, Leavitt BR, Roos RA, Durr A, Craufurd D, Kennard C, Hicks SL, Fox NC, Scahill RI, Borowsky B, Tobin AJ, Rosas HD, Johnson H, Reilmann R, Landwehrmeyer B, Stout JC. TRACK-HD investigators. Biological and clinical manifestations of Huntington's dis- 
ease in the longitudinal TRACK-HD study: Cross-sectional analysis of baseline data. Lancet Neurol. 2009;8(9):791.

[101] Gizewski ER, Schanze T, Bolle I, de Greiff A, Forsting M, Laube T. Visualization of the visual cortex in minipigs using fMRI. Res Vet Sci. 2007;82(3):281.

[102] Vial F, Serriere S, Barantin L, Montharu J, Nadal-Desbarats L, Pourcelot L, Seguin F. A newborn piglet study of moderate hypoxic-ischemic brain injury by $1 \mathrm{H}-\mathrm{MRS}$ and MRI. Magn Reson Imaging. 2004;22(4):457.

[103] Watanabe H, Andersen F, Simonsen CZ, Evans SM, Gjedde A, Cumming P. DaNeX Study Group. MR-based statistical atlas of the Göttingen minipig brain. Neuroimage. 2001;14(5):1089.

[104] Ishizu K, Smith DF, Bender D, Danielsen E, Hansen SB, Wong DF, Cumming P, Gjedde A. Positron emission tomography of radioligand binding in porcine striatum in vivo Haloperidol inhibition linked to endogenous ligand release. Synapse. 2000;38(1):87.

[105] Rosa-Neto P, Doudet DJ, Cumming P. Gradients of dopamine D1- and D2/3-binding sites in the basal ganglia of pig and monkey measured by PET. Neuroimage. 2004;22(3):1076.
[106] Cumming P, Rosa-Neto P, Watanabe H, Smith D, Bender D, Clarke PB, Gjedde A. 24.Effects of acute nicotine on hemodynamics and binding of (11C) raclopride to dopamine D2,3 receptors in pig brain. Neuroimage. 2003;19(3): 1127.

[107] Gonzalo-Orden JM, Díez A, Altónaga JR, Gonzalo JM, Orden MA. Computed tomographic findings in ovine coenurosis. Vet Radiol Ultrasound. 1999;40(5):441.

[108] Van Raamsdonk JM, Gibson WT, Pearson J, Murphy Z, Lu G, Leavitt BR, Hayden MR. Body weight is modulated by levels of full-length huntingtin. Hum Mol Genet. 2006;15(9):1513.

[109] Pouladi MA, Stanek LM, Xie Y, Franciosi S, Southwell AL, Deng Y, Butland S, Zhang W, Cheng SH, Shihabuddin LS, Hayden MR. Marked differences in neurochemistry and aggregates despite similar behavioural and neuropathological features of Huntington disease in the full-length BACHD and YAC128 mice. Hum Mol Genet. 2012;21(10):2219.

[110] Comparative Anatomy and Histology: A Mouse and Human Atlas; edited by Piper Treuting, Suzanne M. Dintzis, Elsevier, 2011. 